\title{
Exploration on the Application of Henan Traditional Residential Doors \& Windows Decoration Art in Modern Indoor Design
}

\author{
Fuyan $\mathrm{Yu}$ \\ School of Art and Design \\ Huanghe Science and Technology College \\ Zhengzhou, China, 450063
}

\begin{abstract}
By inheriting the aesthetic sense and pursuing the ideals and spiritual demands of Chinese cultural tradition, traditional residential door \& window decorative art is a material carrier of national culture and an important symbolic language of traditional architectural design. It provides inexhaustible design elements for the inheritance and innovation of China's traditional culture. Combining multiple ideas such as nationalism, regionalism, culture, diversity and sustainable development, etc., the use modern design theory and methods for reference actively explore an application method of traditional door \& window decoration elements in decoration design.
\end{abstract}

\section{Keywords—doors \& windows; decoration; application}

\section{ThE VALUE OF TRADITIONAL DOOR \& Windows DECORATION}

In today's information society, new ideological trends of life concepts, continuously affected by foreign culture, impact our traditional culture. In this situation, we shall take innovation in a direction that we hope will not break away from tradition yet still maintain a modern sense. Researching and exploring traditional door \& window decoration and its culture have an important real-world value in promoting and designing localized, decorative art works with modern architectural decoration.

\section{A. Cognitive Value of Traditional Doors \& Windows Decoration}

As an integral part of traditional architecture, traditional door \& window decoration plays an important role in archaeological excavation and the reparation of ancient architecture. Traditional residential decoration is an important carrier of different regional cultures and is of great significance for distinguishing the geographic origin of buildings and some decorative forms. Artistic presentation forms of traditional door \& window decoration are rich, including various folk arts such as wood carving, brick carving, stone carving, calligraphy, painting and paper cutting. Through learning and researching traditional door \& windows decoration, we can more clearly recognize and protect folk arts. Traditional door \& window decoration carries traditional virtues and philosophical culture such as the humanistic consciousness in calligraphy and painting, illusionism and symbolizing analogy, a harmonious spirit with complete sequence, a natural caring, and ethics advocating orders and ranks. No doubt exploring and inheriting traditional door \& window culture is valuable in traditional cultural education.

\section{B. Aesthetic Value of Traditional Door \& Window Decoration}

Traditional door \& window decoration does not only have a rich cultural connotation but also is a perfect combination of function and decoration. Its rich decorative themes have strong humanistic color; programmed animals, plants, figure patterns and textures are not only beautiful in form, but also have mature and perfect design methods in composition, color and process, which reflects higher aesthetic value. Not only that, some door \& window decorative elements can also be regarded as independent art works for appreciation. One door, one animal head appliqué and one pair of stone lions can be applied to the modern architectural decorative environment flexibly as highlights of decoration.

\section{Sentimental Value of Traditional Door \& Window Decoration}

Historic feelings and homeland feelings of traditional door \& window decoration is a spiritual pillar in the continuation of traditional culture. Contents reflected by traditional doors \& windows play an important role in people's emotional relationship and spiritual destination. It has the color and feel of your hometown, shaped by legends told by an old man on loyal and moral subjects. Different regions with different folk customs have a direct and natural reflection in local traditional residential doors \& windows. In modern design, we should borrow the consciousness of time and space from traditional architectural culture, close the distance between humans and the environment, humans and nature, humans and history, and establish an affinitive distance between traditional culture and regional culture, touching on the "hometown" complex in the heart and making busy people find their spiritual destination. 


\section{APPLICATION PRINCIPLES OF TRADITIONAL DOORS \& WINDOWS DECORATION IN MODERN INDOOR DESIGN}

For a modern indoor environment, application carriers of traditional door \& window art mainly include excellent antique door \& window works and high-quality products in current indoor design that have inherited the cultural essence of traditional doors \& windows, remaining traditional elements will still being processed with modern adaptability. After all, traditional door \& window decoration and modern indoor decoration are rooted in different historical conditions and cultural backgrounds; as such, traditional door \& window decoration cannot be copied in the modern environment directly. Therefore, borrowing and applying traditional door \& window techniques shall follow certain principles.

\section{A. Integrity Principle}

Considering problems from a general perspective is always our traditional thinking method. We shall integrate this ability in interior design. Generally interior design involves natural characteristics such as texture, comfort, beauty and ecology and also involves social attributes such as fashion, social functions and humanist approach. Integrity means that interior design shall meet the requirements of these two aspects comprehensively. These two attributes are expressed in the tangible indoor environment and intangible environment; the tangible environment includes the artificial environment such as furniture, displays, components, decoration and greening; the intangible environment mainly refers to the humanistic environment, including historical and social factors, such as culture, customs and tradition, etc. These environmental factors have a large influence on interior design, and only we have considered them integrally to mould comfortable and realistic human environments.

\section{B. Culture Principle}

Containing deep culture, thoughts and feelings of the Chinese nation, Chinese traditional residential door \& window decorative art is an important signal language of traditional architectural decoration. In the creative practice of modern architectural and decorative internationalization and localization, how do we realize inheritance and innovation? Mr. Liang Sicheng proposed earlier that traditional architectural creations should be "Chinese but not old, new but not foreign". In other words, traditional architectural design does not simply imitate Chinese classical architecture, but rather, through deep research into traditional culture, applies its ethos into design. This not only breaks through tight encirclement of current various fashionable images, but also creates a new image rich in Chinese traditional culture.

\section{Technology Principle}

The technology of architectural decoration is modernity from another perspective. Decoration design is the design of space modeling and it is a process of transferring thought, culture and feelings through design symbols. Thorough what symbol can we fuse modern architectural structural space? And how can we fuse a modern living environment? How can we properly express unique " form", peculiar "color" and specific "artistic conception" of traditional door \& windows element? These are what we consider during inheritance and innovation of door \& window decorative art. Insisting on the technology principle, one can coordinate traditional door \& window elements and new materials of modern architectural decoration, new change, new process of new technology and times technology, and open up a new way to innovate traditional door $\&$ window decorative art.

\section{Functionalism Principle}

Everything must have its contents for its existence. In the field of architecture, the existing contents of an indoor space manifest themselves in the summation of their material function and the internal elements of their spiritual function. The material function of space mainly manifests itself in the behavioral requirements and life requirements of a human within an indoor space. The spiritual function manifests itself through multiple aspects and multiple layers, such as emotional aspects, physiology, safety, etc. History has proven that the design principle of the functionalism principle has rationality and necessity in social needs and industrialization.

\section{E. Humanism Principle}

Indoor space is created by humans and used by humans. Humanism, therefore, means that being people-oriented is the fundamental starting point of design. In design, a human's requirements, including materials requirements and spiritual requirements within a living space, shall be always the most important. Meanwhile, the building of indoor spaces shall meet human's physiological and psychological needs and comprehensively deal with various relationships such as human-to-human and human-to-environment. Additionally the construction of indoor spaces can address various problems such as function, comfort and beauty, environment and atmosphere, etc.

\section{APPLICATION METHOD OF TRADITIONAL DOORS \& WINDOWS DECORATION IN MODERN INDOOR DESIGN}

Traditional residential door \& window decorative art has received more and more attention due to its own value and practical significance. The inheritance and innovation of traditional door \& window decorative art does not involve simply the mechanical application, but also expresses the traditional language of door \& window decoration with modern means and fuses them into modern architecture and interior design to form one organic integrity.

\section{A. Selection of Traditional Door \& Window Decoration Elements}

Traditional door \& window decoration elements go through an abundance of content inherited and accumulated over thousands of years. Content and forms are highly blended, specifically the stylization and fixedly defined modeling, color, material, and technology. Some good decoration forms and treatment techniques can be directly 
applied to modern decoration design. Traditional residential door \& window decoration is decreasing and disappearing, and we cannot directly select them as a decoration completely, but rather focus more on absorbing elements of its decorative patterns, textures and modeling; the application of decorative processes, decorative connotations, and decorative styles remains a common pursuit. For example, traditional stone carving, wood carving, brick carving, and animal head appliqué are also arts and crafts with high aesthetic value that can be transferred into indoor furnishings or directly applied to decoration articles; the graceful pattern and texture of door \& window decoration also can be applied to modern carving processes and directly shown in modern decoration; direct selection of traditional door-gods and couplets increases humanistic connotations for the whole space and does not reduce modernistic expression while highlighting national features. Two points shall be examined closely in regards to residential door \& window decoration: firstly, the quantity shall not be large; multiple residential door \& window decorative symbols cannot be piled up and should be stopped when appropriate. Secondly, attention shall be paid to the coinciding of modern decorative images and the decoration theme; especially paying attention to cultural meaning of door \& window decoration, and it should not differ too greatly.

\section{B. Symbolization of Traditional Doors \& Windows Decoration Elements}

Traditional door \& window decoration is the product of different times and different life style. Changing the decoration object also promotes the necessary renewal of decoration; the dividing line between aesthetic sentiments also gives developmental force to the traditional doors \& windows decoration. Therefore, it is necessary to realize innovation with the field of door $\&$ window decorative forms. We can scan decorative images for patterns, modeling, and components of traditional door \& window decoration and extract classical and traditional elements and use them to redesign. For example, doornails, decorative cylinders, and partition doors cannot only have decorative elements of modeling, but also have the decorative elements of colors and materials. The extracted decorative elements are resigned and further stylized as decorative symbols and applied to modern decoration. The specific method can start from the following aspects:

\section{1) Induction and simplification}

Seek systematic elements in door \& window decoration, extract and purify elements from materials, make complex elements simple, and seek a definition and typicality of the image characteristics. Simplify repeated, tedious, and secondary elements in traditional residential door \& window decoration to acquire purity and sense of beauty in form. For example, the form of a door head; simplify the brick carving, the closure eaves, and conclude the construction of the door head's modeling. Then, highlight the door head's structural feature, simplify it, and present it using modern materials. This technique is performed to embellish the extraction and abstract simplification of a whole or part of a traditional form. The principle is that, though the traditional form can be lost, the traditional charm is permanent; the tradition remains extended and developed on the basis of combining with modern function and technology.

\section{2) Symbol collage}

If its characteristics are too abstract, split or deform traditional components familiar to humans and make them become certain symbols with typical meaning or symbolic meaning, and adopt a collage of indoor elements so that the new and the old, the present and the ancient, are connected. This technique is different from traditional decoration application; it emphasizes repetition, exaggeration, and deformation and conforms to metaphors established in symbolic habit. On the basis of simplification, emphasis, exaggeration, idealization, grasping morphological characteristics and strengthening the manifestation. The manifestation can be an exaggeration and deformation based on form and structure or on feelings, or it can be an exaggeration and deformation based on geometrical morphology. If a protuberant circular doornail is changed to a square concave hole, then the square concave hole is arranged according to the vertical and horizontal approach of traditional doornail. Through deformation, decorative form is not only born out of tradition but also remains different from tradition and can be acquired, an important method in the modernization of traditional door \& window decoration language.

\section{3) Shift combination}

Shift combination is achieved by making the whole or a part overlap the different modeling of door \& window decorative elements to form taste through clever composition. By decorating the most essential parts with the most traditional characteristics of residential door \& window decoration, it can conform to modern aesthetical standards. Reconstruction through modern design methods plus modern composition modes has a modern sense as well as the decorative form of national tradition. One should transplant and graft historical culture and make it become one new artistic image. In design, sometimes we borrow some elements of foreign culture and make it coexist with local cultural elements; sometimes we widely gather various elements of ancient and present cultural heritage and graft them together to create one new creative technique of borrowing tradition. This mutual transplanting and grafting of abstract modeling of architectural doors, leaking windows in classical gardens, or wood carvings of traditional residential window decoration are elements of this creative technique.

\section{4) Multiple reconstruction}

The characteristic method of "multiple reconstruction" is to break down narrow traditional cultural concepts and design products that shall inherit all the excellent cultural inheritance of mankind while selecting cultural elements that are conducive to the theme being presented. The cultural elements can be broken up beforehand and reconstructed through multiples means such as apposition, contrast, staggering, and penetration in order to acquire an unexpected effect. Traditional residential door \& window decorative art has undergone a long historical accumulation; its decorative forms are multiple and its patterns are rich-- the technology 
is excellent and contains extremely high artistic aesthetic value. However, the art of decoration has the defects of oldfashionable form and fussy modeling contrary to elements of modern people's lives, style, and aesthetic tendencies. Therefore, we need to extract, summarize and redesign it. A brand new form, integrated with characteristics of the original shape that are provided by the technique of breaking up and reconstruction, shall make modern design possess modernity and emits traditional favor.

\section{Multiple Uses of New Materials and Traditional Materials}

No matter from which form or design angle we start, materials application is an important base of design. It is difficult to be extensive when decorating a Chinese-style interior with traditional materials; hence we should make bold attempts with new materials and attempt to express the classical forms and ancient themes through modern materials. Moreover, expressing the meaning of original symbols by applying new materials gives rich expression to the space and makes the space posses modernity.

The use of different materials means different textures and different techniques. Emotional tendencies and materials can set up an interaction and communication bridge between the traditional and the modern. By grasping properties, processing the technology of various materials and their characteristics, and by combining specifics of the environment, the reconstructed traditional door \& window decoration can be expressed through modern materials such as glasses, stainless steel and metal plates.

\section{Recombination of Colors}

Decoration colors of traditional residential doors \& windows are fixed by habitual color matching. This can be used in patterns with that have a very strong modern form in order to express traditional charm. Colors also can be extracted for re-matching and reconstruction along with the reconstruction of shape. Through combining characteristics of color with a change in the materials, the new design can still express the atmosphere of national tradition despite the different means used in its creation.

\section{CONCLUSION}

Henan's traditional residential door \& window decorative art has been widely applied in contemporary architectural interior design and is a specific phenomenon in the developmental process of decoration art. Traditional door \& window design in contemporary interior design transfers complete rich images to humans and expects that people can realize sustenance from China's traditional culture through this art form in a contemporary indoor space. The inheritance and development of traditional door \& window decoration art is not simply following, but also expressing the traditional door \& window decorative language by using modern means and blending them into modern design to create an organic whole. Modern interior design does not only need to inherit the uniqueness of national art, but also needs to reflect the individuality of modern people and the pursuit of fashion.
We should choose and inherit the best and better realize exploitation and innovation of traditional art simultaneously.

\section{REFERENCES}

[1] Shen Fuxi. Architectural Art History [M]. Shanghai Brilliant Punishing House, 2010.

[2] Ma Weidu. Classical Chinese Doors\& Windows[M]. Beijing: China Architecture\& Building Press, 2010.

[3] Lou Qingxi. Beauty of Doors \&Windows[M]. SDX Joint Publishing Company, 2008. 